\title{
Editorial
}

\section{Ian Bekker}

North-West University, Potchefstroom Campus

E-mail: Ian.Bekker@nwu.ac.za

It is with great satisfaction that I write this editorial for the second special issue of SPIL Plus (and third special issue overall) dedicated to the Southern African Microlinguistics Workshop series, which began at the Potchefstroom Campus of the North-West University in 2012. At the time of writing this editorial, SAMWOP-4 has already been held from 27-29 November 2015 at Rhodes University, Grahamstown, while SAMWOP-5 will be held in late 2016 at either the Potchefstroom Campus of the North-West University or the University of the Free State. From the growing number of participants, both local and international, it appears that the workshop series is filling an important gap on the South(ern) African linguistics "scene".

SAMWOP-3, to which this particular special issue is aligned, was itself held at the Potchefstroom Campus of the North-West University from 24-27 November 2014. One of the unique features of this workshop was a hugely successful debate between Prof. Mark de Vos from Rhodes University (representing the nativist position) and Prof. Bertus van Rooy from the Vaal Triangle Campus of the North-West University (representing the emergentist position). The first two articles in this special issue - De Vos and Van Rooy \& Kruger, respectively - are essentially re-formulations of the two sides of this debate.

A new feature introduced to this special issue is the inclusion of short open reviews (and replies) to articles in the previous SAMWOP special issue (in this case, SAMWOP-2). This issue thus begins with two reviews of articles which appeared in the previous special edition, as well as short replies by the authors of the original articles. We hope to continue with this practice of what is in effect a form of fruitful debate.

Moving to the full articles, we begin with the first article based on the debate mentioned above: Mark de Vos attempts to outline the nativist position by looking at the fundamental research questions that define it. He argues that nativism is thus one possible coherent way of navigating through these questions; other routes through them may also be possible. Consequently, there may be new spaces for rapprochement between different linguistic disciplines, but these are often concealed by our scientific discourses.

On the other hand, Bertus van Rooy and Haidee Kruger present a defence of emergentism as an alternative linguistic paradigm to nativism. They set out the key assumptions of nativism that they disagree with, before offering an exposition of the emergentist alternative. They 
demonstrate the application and value of the emergentist paradigm through a corpus-based, construction grammar analysis of the phenomenon of wh-extraction in Afrikaans. They argue that a lexically based micro-level construction is adequate to account for the process, rather than a more complex and abstract movement analysis.

In his article, Jochen Zeller compares two different ways in which syntactic movement is analysed in the Minimalist Program. While the standard approach takes movement of an element to be the result of attraction by a grammatical feature of the target, alternative analyses view syntactic movement as being driven by features of the moving element. Zeller's analysis of various A-bar movement constructions in the Bantu language Zulu provides evidence for the latter type of analysis by showing that only DPs that undergo movement in Zulu are active Goals for the functional head responsible for object agreement. This entails that the "mobility" of a DP must be encoded as a property of this DP before it undergoes movement.

In Lande Botha's article, the findings of her corpus study suggest that the use of some as determiner of plural nouns in BSAfE, in contexts where no determiner would be expected, can be ascribed to an extension of its quantifying function to an article-like indefiniteness marking function.

Xitsonga has certain Aspectual Auxiliary verbs (AA verbs) that appear with double subject agreement. In the next article, Seunghun Lee and Crous Hlungwani aim to describe morphosyntactic properties of AA verb constructions in a systematic manner. While AA verbs are marked with tense, aspect, mood as well as negation and relative clause markers, the lexical verb itself is marked with verbal extensions.

Finally, Daan Wissing, Wikus Pienaar and Daniel van Niekerk report on the acoustic characteristics of the Afrikaans alveolar fricative /s/. Their study reveals that - especially in the pronunciation of young, white Afrikaans-speakers - /s/ is palatalised progressively when preceded by $/ \mathrm{r} /$. This finding might be indicative of a definite change in the Afrikaans consonant system.

The articles provided in this special issue represent, I believe, the state-of-the-art in Southern African microlinguistics, regardless of how we might wish to define this term. I hope that future workshops and special issues will serve to facilitate equally valuable research. 